- ACORN Australan College peroperative nuRses | JOURNAL OF PERIOPERATIVE NURSING

\title{
Enhanced recovery after surgery in Australia: A classic example of an evidence-practice gap
}

Follow this and additional works at: https://www.journal.acorn.org.au/jpn

Part of the Health Services Administration Commons, Health Services Research Commons, and the Perioperative, Operating Room and Surgical Nursing Commons

(c) (i)

This work is licensed under a Creative Commons Attribution 4.0 License.

\section{Recommended Citation}

Duff, Jed (2020) "Enhanced recovery after surgery in Australia: A classic example of an evidence-practice gap," Journal of Perioperative Nursing: Vol. 33 : Iss. 4 , Article 5.

Available at: https://doi.org/10.26550/2209-1092.1109

https://www.journal.acorn.org.au/jpn/vol33/iss4/5

This Editorial is brought to you for free and open access by Journal of Perioperative Nursing. It has been accepted for inclusion in Journal of Perioperative Nursing by an authorized editor of Journal of Perioperative Nursing. 
Professor Jed Duff

PhD, RN, FACORN

Editor, Journal of Perioperative Nursing

Professor, School of Nursing Faculty of Health, Queensland University of Technology Nursing and Midwifery Research Centre, Royal Brisbane and Women's Hospital

journaleditor@acorn.org.au

\section{Enhanced recovery after surgery in Australia: A classic example of an evidence-practice gap}

Enhanced recovery after surgery (ERAS) pathways - often referred to as fast-track programs - are multidisciplinary, evidence-based perioperative pathways, designed to achieve early recovery for patients undergoing major surgery. ERAS has been described as a surgical revolution because of the benefits it produces. A recent systematic review found, on average, ERAS pathways reduce length of stay by 2.3 days and case costs by $\$ 639.00$; without adverse impact on mortality, adverse events, or readmissions'.

Despite the clear benefits to patients and the health system, there is little evidence that ERAS pathways are routinely used in Australian hospitals. Some people claim they are using them, but usually what they mean is that individual clinicians are adhering to specific elements of a pathway. This is not ERAS. Improved outcomes demonstrated by ERAS pathways are the result of consistent application of all elements across the entire surgical period (from referral for surgery to recovery). ERAS pathways vary depending on the category of surgery, but broadly speaking they include the following:

- preoperative patient education

- preoperative optimisation of health

- perioperative nutritional supplements

- antimicrobial measures and venous thromboembolism prophylaxis

- multimodal antiemetics and analgesia

- avoidance of bowel preparation, nasogastric tubes and drains

- early oral nutrition and mobilisation.

You can see from the pathway elements above that ERAS requires the commitment of the entire surgical team, including surgeons, nurses, anaesthetists, allied health professionals, administrative staff and managers. In Australia, surgical care is extremely siloed. Care provided in the perioperative department is distinct and separate from that provided in the preadmission clinics or the surgical wards. This fragmentation of care delivery is a barrier to the uptake of ERAS and an impediment to the good governance of surgical services.

Besides the patient, the one person who traverses the entire surgical period is the surgeon. This would make surgeons best placed to lead the introduction of ERAS into hospitals. Unfortunately, in Australia, there is no incentive or support for them to lead such a significant practice change. The other entity who should have an interest in implementing ERAS is government. The efficiencies and cost savings that result from the introduction of ERAS have been a major driver for the Canadian, United Kingdom (UK) and New Zealand governments. Even the United Stated of America (USA) system, for all its shortcomings, incentivises ERAS pathways. This isn't the case in Australia.

The international ERAS Society website (erassociety.org) has a wealth of information about the 
ERAS movement and evidence-based pathways for every conceivable category of surgery. On the website, you can see that many advanced health systems, such as those in Canada, the UK and USA, have their own national ERAS Society Chapter and ERAS Centres of Excellence. Australian representation in the ERAS movement is noticeably absent. I'm sure there are dedicated professionals across the country trying to implement ERAS, but we don't appear to have a coordinated national approach.

ERAS uptake in Australia is a classic example of a gap between evidence and practice. There are over 20 years of evidence, yet we still haven't adopted it consistently into routine practice. When we try to address evidence-practice gaps, we look to identify the barriers. A systematic review reported three common barriers:

1. resistance to change from frontline clinicians

2. not enough resources allocated to implementation

3. external factors, like patient complexity or hospital location ${ }^{2}$

I acknowledge that these barriers exist but, to me, they are a symptom of a greater problem. The fact that there is no national push to implement ERAS despite all the benefits demonstrates that surgical care is not a priority in Australia.
I do not know what the solution is to this problem, but I suggest that rather than focusing on what we should do, maybe we should focus on what we should be. Let me pose this thought experiment. What would our surgical services need to be to adopt ERAS? Here are some things that come to mind:

- evidence-based

- patient-focused

- outcomes-oriented

- interdisciplinary

- collaborative

- integrated.

If there are examples where ERAS has been implemented in facilities or across health services, then I encourage you to share your experiences here in the Journal of Perioperative Nursing. These reports can be from Australia or other countries, and they can include successful or unsuccessful implementation attempts. For my part, I have decided to write an editorial every year until we have a wide-scale adoption of ERAS in Australia.

\section{References}

1. Zhang X, Yang J, Chen X, Du L, Li K, Zhou $Y$. Enhanced recovery after surgery on multiple clinical outcomes: Umbrella review of systematic reviews and metaanalyses. Medicine vol. 99,29 (2020): e20983. doi:10.1097/MD.0000000000020983.

2. Stone AB, Yuan CT, Rosen MA, Grant MC, Benishek LE, Hanahan E, et al. Barriers to and facilitators of implementing enhanced recovery pathways using an implementation framework: A systematic review. JAMA Surg. 2018;153(3):270-279. doi:10.1001/ jamasurg.2017.5565. 